\title{
Self-Regulation: An Individual Difference Perspective
}

Rick H. Hoyle and Hannah Moshontz

Department of Psychology and Neuroscience, Duke University, Durham, NC, USA

Draft of chapter to appear in J. Y. Shah (Ed.), Frontiers of Social Psychology: Self-regulation. New York: Routledge.

Self-regulation is the means by which people manage goal-directed behavior. ${ }^{1}$ The simplicity of this statement belies the extensive array of psychological structures and mechanisms that support autonomous behavior that aims to bring people closer to a desired state, prevent them from experiencing an undesired state, or help them maintain a desired (or at least acceptable) state they have reached. These states, or goals, are the target of self-regulation. Contributing to their behavioral pursuit are cognitive, motivational, and affective systems that support critical self-regulatory functions such as forethought, planning, monitoring, and selfevaluation. Although these functions, and the systems that support them, are common across people, the particular ways in which they operate, individually and in relation to each other, vary widely across people. This variability, in part, explains why some people are more effective than others at managing pursuit of their goals. More fundamentally, however, it reflects the different psychological strengths, challenges, and preferences that influence how people routinely selfregulate their behavior. Our goal in this chapter is to review a subset of the many individual differences that are relevant for self-regulation. Although chronic environmental factors and basic individual differences such as age, culture, and intelligence account for some variability in self-regulation, our focus is psychological constructs and behavioral tendencies that are relevant for specific self-regulatory functions.

\footnotetext{
${ }^{1}$ Although the many perspectives on self-regulation differ in the particulars, nearly all view the management of goal pursuit as the defining feature. For our purposes, noting this simple but defining feature is sufficient. Interested readers will find in the literature multiple perspectives on self-regulation that build on this defining feature to offer detailed accounts of the specific processes and strategies that it entails (e.g., Berkman, Livingston, \& Kahn, 2017; Brown, 1998; Carver \& Scheier, 1982; Fishbach \& Zhang, 2009; Karoly, 1993; Kruglanski et al., 2000).
} 
The chapter is organized as follows. In the first part, to provide context for the primary focus on individual differences linked to specific self-regulatory functions, we review attempts to capture general effectiveness or skill at self-regulation. The heart of the chapter focuses on an array of constructs relevant for specific self-regulatory functions. The presentation is organized according to the process domain for which the construct is most clearly relevant: behavior, cognition, or motivation and emotion. A substantial number of relevant individual differences crosscut these domains or do not fit cleanly into either of them. We review a representative subset of these constructs in the final section of the chapter.

\section{Individual Differences in Effectiveness}

The fact that some people are better at self-regulation than others is undeniable. Whereas some people are able to lose weight when they want to, live within their means, and routinely meet obligations in a timely manner, other people seem to be unable to manage their diet and finances or meet their obligations. Attempts at capturing individual differences in general effectiveness at managing goal-directed behavior have not yielded a widely-accepted conceptual model or approach. The absence of a model of or approach to effectiveness likely stems, at least in part, from the many features of self-regulation for which effectiveness might be judged. For example, self-regulation may be ineffective because it requires the management of a poorly articulated goal (Locke \& Latham, 2006). For the management of a well-articulated goal, effective self-regulation requires the ability to enact or avoid behaviors that promote progress toward the goal as well as self-monitoring of and adjustments to those behaviors based on their effects on progress (Baumeister, 2018). More generally, effectiveness could be judged by outcomes that reflect goals nearly everyone at certain points in the lifespan is assumed to be pursuing (e.g., social and academic competence during adolescence; Mischel, Shoda, \& Peake, 
1988; Shoda, Mischel, \& Peake, 1990). For the purpose of our review, while acknowledging the need to understand effectiveness at the level of self-regulatory process, we focus on effectiveness as making progress toward and ultimately achieving goals that result in adaptive outcomes.

The appeal of a general model of effectiveness at self-regulation, especially if accompanied by a means of assessing it, is evident. Because of the clear relevance of selfregulation for academic performance, the ability to characterize and measure general skill at selfregulation alongside cognitive ability could provide a more complete picture of student potential and needs, especially in young children (Blair \& Raver, 2015). In the workplace, skill at selfregulation contributes to job performance (Porath \& Bateman, 2006) and resilience in the face of work-related stress (Rothstein, McLarnon, \& King, 2016). The ability to characterize general skill at self-regulation could provide useful information for selecting from a pool of job applicants or for equipping workers who are especially vulnerable to stressors in the workplace.

The modest progress on characterizing general skill at self-regulation has focused primarily on measurement. Thus, although our primary focus in the chapter is on constructs and processes, we necessarily focus on measurement with respect to individual differences in general effectiveness or skill at self-regulation. The most noteworthy attempt at assessing overall skill is reflected in the Self-Regulation Questionnaire (SRQ), which was designed to capture all aspects of a process-based model of self-regulation (Brown, Miller, \& Lawendowski, 1999). Building on Kanfer's (1970a, 1970b) detailed account of steps involved in the self-regulation of behavior, the 63 items query respondents about the degree to which they routinely succeed at finding and evaluating information relevant to the self-regulatory challenge; initiating behavioral change; exploring ways to change and finding the motivation to pursue them; developing and following through with plans to achieve the desired change; and evaluating the effectiveness of the plan 
with respect to the focal behavior (Miller \& Brown, 1991). The authors not only recommend the use of a total score to characterize self-regulatory functioning, they provide score ranges corresponding to high, moderate, and low (impaired) functioning. Despite the grounding of this work in a detailed model of self-regulation, the construct as reflected in scores on the SRQ has not found acceptance as a general characterization of self-regulatory skill.

An alternative approach to characterizing individual differences in general effectiveness at self-regulation is to interpret scores on measures of trait self-control as reflecting the broader set of activities involved in self-regulation. We discuss trait self-control in some detail later in the chapter. For our purposes in this section, we simply note it is not uncommon among social psychologists to describe people who score high or low on a trait self-control scale as good or bad self-regulators, respectively (e.g., vanDellen, Shah, Leander, Delose, \& Bornstein, 2015). In support of this practice is the observation that, although such measures, when the items are interpreted literally, do not appear to capture critical features of self-regulation such as planning and monitoring of progress, scores on the measures predict behavior that reflects these features (e.g., Hofmann, Baumeister, Förster, \& Vohs, 2012). Thus, the items appear to be tapping a latent construct that includes many features of the self-regulation construct. For that reason, the tendency among social psychologists to treat self-control and self-regulation as synonymous, at least with respect to measurement, appears justified.

A promising approach to capturing individual differences in general effectiveness or skill at self-regulation is to administer multiple measures of relevant constructs such as those reviewed in the next two sections of the chapter and use latent variable modeling to extract the underlying common source of variance in responses. Although researchers are increasingly making use of multiple measures as a means of capturing the full breadth of the self-regulation 
construct (e.g., Sevincer, Mehl, \& Oettingen, 2017), it is rare to see the use of statistical modeling strategies that aim to model a general factor presumed to reflect individual differences in self-regulation. Although the value of this approach is more theoretical than practical, it may lead to a better understanding of how specific skills and challenges relevant for self-regulation operate in tandem to determine overall effectiveness at self-regulation.

\section{Specific Individual Differences}

In this section of the chapter, we highlight some of the many individual differences that affect how and when self-regulation is enacted and its effectiveness when enacted. We position each individual difference in one of three categories that corresponds to its most salient feature or function, acknowledging that many manifest secondary features that reflect the other categories. The categories—-behavior, cognition, and motivation and emotion — are satisfactory for describing most, but not all, of the individual differences at play in self-regulation. Those that do not fit into this organizational framework are covered later in the chapter.

\section{Behavior}

Remaining on course in the pursuit of goals frequently requires managing behavior. For example, a goal to achieve good physical health may require eating or not eating certain foods, engaging in physically demanding behavior on a regular basis, or taking prescribed medications. Many such behaviors involve choice. For example, making menu selections that serve the goal of good physical health may require choosing between unhealthy-but-satisfying and healthy-butunappealing options. Thus, self-regulating behavior in the service of a goal may require simultaneously enacting and foregoing certain behaviors. When circumstances that make goalconsistent behavior difficult cannot be avoided, self-control is required. In many instances, selfcontrol takes the form of choosing a behavior that is less appealing than an alternative behavior 
in the moment but that will, in the long run, result in progress toward achieving the goal. Also, impulses that arise within the person can lead to goal-inconsistent behavior and must be managed if progress is to be made. Sometimes, especially in the case of challenging goals that require prolonged commitment and effort, continued pursuit of the goal is unrealistic, unwise, or unappealing to the person. In such cases, the behavioral choice to be made is whether to persist in pursuit of the goal or disengage from pursuit. Although these behavioral processes are required of all people when pursing goals, there are clear individual differences in how well or poorly people manage them. In the remainder of this section we review conceptual models of stable tendencies in how well these behavioral processes are managed.

\section{Self-Control}

Self-control is the quintessential individual difference of relevance for self-regulation. Other individual differences we describe have relevance for self-regulation but have more general significance for behavior and functioning. Self-control is nearly always in the service of self-regulation. Indeed, as noted earlier, often it is treated as synonymous with self-regulation. Here we take a narrow view that is more true to the conceptual definitions (as opposed to measures) of self-regulation and self-control.

Self-control is often conceptualized as overriding a temptation or desire in favor of a salient goal or intention (e.g., Muraven \& Baumeister, 2000). At the trait level self-control is the general tendency to behave in this manner. Owing to the influential work on ego depletion by Roy Baumeister and colleagues (e.g., Baumeister, Bratslavsky, Muraven, \& Tice, 1998), selfcontrol has received widespread attention from scholars across the psychological sciences for more than two decades. That increased attention has resulted in expanded conceptual models that add to the classic notion of self-control as overriding temptations (e.g., Duckworth, 2011; Hoyle 
\& Davisson, 2016; Inzlicht \& Schmeichel, 2016). Trait self-control is the general tendency to resist impulses, cravings, habits, and norms that would lead to action or inaction that undermines the pursuit of personal goals (Hoyle \& Davisson, 2016). Sometimes, an act of self-control involves nothing more than avoiding or otherwise abstaining from behaviors that are inconsistent with an active goal (e.g., declining an offer of dessert while trying to lose weight). At other times, self-control might involve engaging in goal-consistent behavior that is challenging, unpleasant, or otherwise, in the moment, unappealing (e.g., leaving a warm apartment for a long run in the cold). Self-control might also manifest as continued goal-consistent behavior despite boredom, lack of motivation, or, in the moment, unpleasantness (e.g., seeing a workout through to the end on a day when motivation is low and challenge is high).

The relevance of individual differences in self-control for self-regulation is clear. A significant concern in the general management of goal pursuit is dealing with immediate challenges to pursuit. For example, the success of careful planning and disciplined execution of the plan in order to complete a long-term project may be threatened by an offer to join a close friend on a weekend trip or a loss of interest as work on the project becomes tedious. People high in self-control are more likely than their low-self-control counterparts to turn away from temptations and push forward despite a loss of interest, increasing the likelihood of selfregulatory success. In such cases it is clear that self-control is not synonymous with selfregulation but clearly essential for it. However, when the goal in question is short-term and immediate in nature (e.g., spend an evening out with friends without drinking to intoxication), self-control and self-regulation converge. In either case, it is clear that people who are generally good at self-control are likely to be effective at behavioral self-regulation.

\section{Delay of Gratification}


Delay of gratification is a particular form of self-control that warrants specific attention. Although delay of gratification and other intertemporal choices are frequently studied in laboratory settings under varying conditions (for a review, see Berns, Laibson, \& Loewenstein, 2007), it is evident that some people are routinely better at foregoing an immediately available small reward in favor of a larger reward at a later time. Much of the work on individual differences in delay of gratification has focused on the prediction of behaviors and outcomes requiring effective self-regulation from delay of gratification during childhood. For instance, the ability to delay gratification early in life is associated with a variety of positive outcomes during adolescence, including higher college entrance exam scores (Shoda et al., 1990), greater social competence, and more effective emotional coping skills (Mischel et al., 1988). Conversely, the relative inability to delay gratification is associated with increased likelihood of being overweight in adolescence (Seeyave et al., 2009), among other negative outcomes. Because effective self-regulation often requires choosing a behavior that will pay off in goal progress at a later time over a behavior with an immediate pay-off, the ability to delay gratification facilitates self-regulation. It also reflects an ability to think about the potential future consequences of behavior, a form of cognition discussed later in the chapter.

\section{Persistence and Disengagement}

It seems evident that effective self-regulation often requires persistence. The realization of some personal goals may require behaviors that are difficult or unpleasant. In some instances these behaviors must be enacted repeatedly or continuously over extended periods of time in order to make progress in the pursuit of an important goal. In such cases, goal pursuit may be met by some goal-opponent force, which is any internal or external factor that undermines pursuit (e.g., goal difficulty, negative feedback, costs associated with pursuit, environmental 
constraints; Klinger, 1975). Continuation of pursuit in such conditions requires persistence. Less evident is the reality that sometimes the continued pursuit of a goal is ineffective, too costly, or otherwise unwise. In such cases, effective self-regulation involves disengaging from pursuit of the goal and potentially abandoning it altogether.

Persistence receives scant attention in models of self-regulation, but it is an important behavioral tendency that accounts for substantial variation in self-regulatory effectiveness. Most failures of goal attainment can be described as resulting from premature disengagement from pursuit. Occasionally, people disengage from goal pursuit after making a deliberate decision to stop pursuing goals after lack of progress and negative feedback (Brandstatter \& Schuler, 2013). When goals are impossible, excessively costly, or not sufficiently valuable, disengaging is an adaptive self-regulatory response (Wrosch, Scheier, Miller, Schulz, \& Carver, 2003). However, more often, people stop pursuing goals in a less controlled and deliberate manner (that is, they “quit"). These sorts of cessations occur when pursuers intend to remain engaged in pursuit but fail to, or when they disengage without conscious awareness or intention. Little is known about how people differently approach disengagement, and whether some methods of disengaging are better than others. However, it is clear that disengagement decisions are consequential. Our most important and valued goals are difficult and take time to achieve, requiring persistence in the face of doubts, difficulties, aversiveness, inconveniences, and interferences.

People reliably differ in their propensity to persist. Most simply, this variation may be evident in the extent to which people stay engaged in pursuit when they intend to do so. The general tendency to persist when challenged is evident in some models of personality (e.g., Cloninger, Przybeck, Svrakic, \& Wetzel, 1994). It is central in narrower constructs focused more specifically on goal pursuit such as grit, which focuses specifically on the pursuit of long-term, 
higher order goals (Duckworth, Peterson, Matthews \& Kelly, 2007). Because of the duration of their pursuit, such goals are almost certain to be challenged by goal-opponent forces that require persistence if they are to be attained.

People also differ in how long they remain engaged in pursuit because of their tendency or capacity to make adaptive disengagement decisions or to execute them. There is need for more research in this area, but there are at least two constructs that specifically relate to disengagement decisions and execution. Flexible tenacity refers to the extent to which individuals not only persist, but do so adaptively (Gollwitzer, Parks-Stamm, Jaudas, \& Sheeran, 2007). Another important source of variation related to disengagement is how able people are to stop pursuing a goal once they have decided to, or their goal disengagement capacity (Wrosch et al., 2003). Individual differences in this capacity reflect an ability to stop pursuing a goal and stop thinking about a goal that is unattainable. These individual differences capture different features of a general skill that entails knowing when and how to persist when pursuit of a goal becomes challenging and when to stop pursuing a goal that has been deemed unattainable.

\section{Impulsivity}

One of the most thoroughly studied features of personality of relevance for behavioral self-regulation is impulsivity, or the tendency to act without forethought or planning (Dickman, 1990). Impulsivity is detrimental to effective self-regulation in two ways. It is predictive of a host of behaviors that threaten adaptive goal pursuit including substance use, sexual risk-taking, and aggressive behavior (e.g., Hoyle, Fejfar, \& Miller, 2000). More generally, impulsivity runs counter to the basic processes of forethought and planning that serve as the starting point for most instances of self-regulation. The absence of forethought and planning characteristic of impulsivity also minimizes the value of self-reflection following the enactment of goal-relevant 
behavior, as information about the consequences of behavior cannot influence future behavior when there is no forethought or planning.

Psychometric studies of the many measures of impulsivity have led to a more detailed conceptualization than simply acting without thinking and, as a consequence, additional indications of its relevance for self-regulation. The most thorough-going analysis indicates four features of the impulsivity construct (Whiteside \& Lynam, 2001). People who are high in impulsivity have a tendency to give in to impulses that are accompanied by strong emotion. They are unlikely to consider the consequences of behavior before acting. They are generally unable to persist when bored or fatigued. And they feel a general draw toward activities that are novel and stimulating. Each of these features of the construct have relevance for self-regulation. The lack of impulse control when emotions are high and the tendency to ignore consequences of behavior before acting are likely to result in behavior that moves people away from rather than toward adaptive goals. A general inability to tolerate boredom or remain on task when tired works against the persistence necessary to continue goal pursuit when confronted with goal-opponent forces.

Although impulsivity generally undermines effective self-regulation, it sometimes does not. For some goals and in some behavioral contexts goal-consistent behavior is most likely in the absence of forethought, suggesting a potential advantage for impulsive people. When quick decision making is required in order to stay on track in goal pursuit, impulsivity-specifically, functional impulsivity-can improve rather than compromise self-regulation (Dickman, 1990). This advantage is evident when two conditions are met: The environment in which the decision is made is predictable, and the decision maker has had sufficient experience in the environment to know its reliable features (Kahneman \& Klein, 2009). In such cases, individual differences in 
this form of impulsivity may serve pursuit of the active goal better than behavior rooted in careful deliberation and planning.

\section{Cognition}

If effective self-regulation generally requires forethought and planning, then the relevance of basic cognitive processes is clear. People differ in how they routinely think about themselves, other people, situations, and goals. Many of these individual differences affect how, and how effectively, people self-regulate their behavior - in the early stages of pursuit when people are selecting goals or planning strategies to achieve them; during goal pursuit, when people can attend and respond to their progress; and after goal pursuit, when they assess themselves and potentially glean information that will transfer to future pursuits. In addition, other, more fundamental, individual differences in cognition apply at all stages of goal pursuit.

\section{Temporal Orientation}

The style of thought most clearly consequential for self-regulation is the extent to which people routinely think about the future. This individual difference has been characterized in several different ways - from the perspectives of social psychologists, cognitive psychologists, and behavioral economists - and is closely related to trait differences in delay of gratification and other intertemporal choices. People who tend to think more about the future and the future consequences of their behavior tend to make decisions that optimize outcomes that manifest in the future (Strathman, Gleicher, Boninger, \& Edwards, 1994). Routinely thinking about the future benefits self-regulation and the attainment of longer-term goals, providing a basis for planning so as to maximize affordances and minimize obstacles to goal pursuit. A general inattentiveness to the future and, relatedly, the role of time in the pursuit of goals, is one explanation for the detrimental effects of impulsivity on self-regulation (Wittmann \& Paulus, 
2008). People with an orientation toward the future are more conscientious and less impulsive than people with an orientation toward the present or past (Park et al., 2016).

\section{Beliefs and Expectations}

As noted in the section on persistence, the pursuit of goals usually involves many pursuit episodes that sometimes take place over extended periods of time. As a result, people have multiple opportunities in the course of pursing a goal to observe the effects of their goal-directed behavior and process that information for potential use in planning or approaching future pursuit episodes. How people process information about past and future pursuit episodes is influenced by individual differences in attributional style and perceptions of self-efficacy.

Although attributions about the causes of outcomes are influenced by features of the performance context, people vary in their general tendency toward specific patterns of attribution regardless of contextual influences. As a result two people may experience the same outcome under similar circumstances but differ in their attributions about the reasons for the outcome. These differences in attributional, or explanatory, style are relevant for self-regulation because they influence motivational and behavioral responses to outcome feedback, especially when that feedback indicates that goal-directed behavior resulted in no progress, or even a step backward, in the pursuit of an important goal. In such cases, attributions may vary in ways that motivate renewed effort or that raise doubts that may lead to disengagement (Weiner, 1979). Specifically, people who are prone to attribute failures in pursuit to aspects of their own behavior that are changeable and under their control are likely to be motivated to renew their efforts. In contrast, people who attribute such failures to forces outside themselves that they are unable to control and that are unlikely to change are likely to experience doubt and a corresponding reduction in motivation to continue pursuit of the goal (Weiner, 1992). 
These individual differences in attributional style, which color evaluations of past behavior, are also evident in expectations about future behavior. People who are dispositionally optimistic tend to attribute successes in pursuit to their own efforts, which they view as under their control and stable over time. This pattern leads to optimism, or the expectation of positive outcomes, with respect to future pursuits. Conversely, people who are dispositionally pessimistic attribute successes in pursuit to forces outside themselves that they feel unable to control and unlikely to repeat in the future. As such, they are generally pessimistic, or inclined to expect negative outcomes, with respect to future pursuits. Critically for self-regulation, dispositional optimism is associated with the exertion of effort, whereas dispositional pessimism is associated with the withdrawal of effort in the face of impediments to pursuit (Carver \& Scheier, 2014).

Related to beliefs about the likely outcome of future pursuits of a goal are people's beliefs about whether they can successfully complete the behaviors necessary to produce progress toward attainment of the goal. Such beliefs are a key element of the social cognitive theory of self-regulation (Bandura, 1991). Perceived self-efficacy as outlined in the theory varies within person from one behavior to the next and even from one instance of a specific behavior to the next. In addition to the within-person variability in self-efficacy beliefs, and moving beyond the theoretical model in which those beliefs are anchored, there is evidence of between-person variability that is relatively stable over time and consistent across behaviors (Schwarzer, 1994). This generalized form of perceived self-efficacy is akin to optimism but reflects generally positive perceptions of one's ability to get things done as opposed to the broader and less behavior-relevant trait of optimism. Although specific goal-directed behaviors are best predicted by self-efficacy beliefs about those behaviors, individual differences in generalized self-efficacy 
are useful for predicting outcomes that reflect effective self-regulation of a range of behaviors such as those that contribute to overall health and well-being (Schwarzer \& Jerusalem, 1995).

\section{Repetitive Thought}

In terms of self-regulation, rumination and worry, two forms of repetitive thought, are opposites of impulsivity. Whereas people who are high in impulsivity routinely act without thinking, people who are prone to ruminate or worry often think without acting. Rumination, or repetitively thinking about the causes and consequences of negative emotional experiences, is focused on problem solving; however, the depth and duration of that thinking exacerbate rather than alleviate the negative experience (Nolen-Hoeksema, 1991). Individual differences in rumination are a risk factor for the onset and recurrence of depression (Wang, Wei, Yang, Xie, Hao, \& Qiu, 2015). Rumination, especially when accompanied by dysphoric mood, undermines effective self-regulation (Nolen-Hoeksema, Wisco, \& Lyubomirsky, 2008). Ruminators are inclined toward overestimating the magnitude of problems. As a result, they are unlikely to implement self-generated plans for addressing them. The tendency of ruminators to share their repetitive but largely unproductive thoughts with others who might offer social support often results in reduced support as others become frustrated by their inaction. Despite the selfregulation-focused cognition characteristic of rumination, people high in trait rumination struggle with self-regulation.

Like rumination, worry is a perseverative, self-focused form of thought that undermines effective self-regulation. Although people who are prone to ruminate are also prone to worry, the effects of the two predilections on self-regulation can be separated (Segerstrom, Tsao, Alden, \& Craske, 2000). Whereas rumination is concerned with past events, worry is concerned with possible future events that often never occur (Nolen-Hoeksema et al., 2008). People who are 
prone to worry often feel uncertain about potentially aversive future events (including the potential ongoing consequences of past events) and are motivated to avoid the emotional distress those events would bring (Servaas, Riese, Ormel, \& Aleman, 2014). Although worry is typically viewed as a unitary construct, psychometric studies of measures of repetitive thought suggest that the construct encompasses multiple tendencies (Davey, 1994; Segerstrom, Roach, Evans, Schipper, \& Darville, 2010). Specifically, worry involves thinking repetitively, thinking about possible negative events, and seeking certainty and solutions to problems. The particular mix of these tendencies may differ for people with identical levels of overall trait worry. Regardless of the mix, the repetitive nature of worried thinking and the generally low likelihood that the feared event will occur as anticipated impede effective self-regulation.

\section{Cognitive Control}

Cognitive control involves a fundamental set of brain-related processes that support adaptive information processing in the service of behavior that is responsive to currently active stimuli, including goals. Cognitive control encompasses a large number of processes, a subset of which we touch on here: executive functions. The executive functions most relevant for selfregulation are updating (or working memory capacity), inhibition, and shifting. There is a clear positive relationship between individual differences in executive functions and behavioral selfregulation. Inhibition shows particular relevance to self-regulation (Miyake, Friedman, Emerson, Witzki and Howerter, 2000), with working memory also playing an important role (Ilkowska \& Engle, 2010). For instance, measures of working memory capacity predict behaviors reflective of effective self-regulation, such as avoiding unwanted but tempting food (Hofmann, Gschwender, Friese, Wiers, \& Schmitt, 2008). Despite the stability of individual differences in executive functions, there is some evidence that interventions that produce improvements in executive 
functioning may temporarily strengthen critical skills involved in self-regulation (Hofmann, Schmeichel, \& Baddeley, 2012). However, more rigorous study and direct evidence for transfer of cognitive training is needed (e.g., Shipstead, Redick \& Engle, 2012; Simons et al., 2016).

\section{Motivation and Emotion}

In addition to differences in behavioral and cognitive styles that have relevance for selfregulation, systematic differences in people's feelings (emotion) and desires (motivation) also influence their effectiveness at and approach to goal pursuit. Though motivation and emotion have received great attention in psychological science-for example, from clinical and cognitive neuroscience - the connections between stable differences in motivation and emotion between people and their self-regulation have received relatively little direct attention. Here, we explore individual differences in motivation and emotion that have relevance for self-regulation.

\section{Affect and Emotion Regulation}

People differ in how they experience, express, and regulate their emotions. Affective states both influence and are influenced by self-regulatory processes like self-control (Baumeister, Zell, Tice, 2007; Tice \& Bratslavsky, 2000). When making decisions, people often consider how their decisions will make them feel. However, these forecasts are often inaccurate, biased by their current emotional states and other assumptions that lead them to overestimate the intensity and duration of the emotions that they will feel, both positive and negative (Wilson \& Gilbert, 2003). Emotions play a particularly large role in intertemporal decisions and other selfcontrol conflicts (Metcalfe \& Mischel, 1999). Contemporary models of self-control go so far as to characterize it as an inherently emotional process (e.g., Inzlicht, Bartholow, \& Hirsh, 2015). Whether one subscribes to this idea or not, it is clear that emotional states affect executive 
functions (Pessoa, 2009) and can interfere with and distract from goal-pursuit processes (Dolcos \& McCarthy, 2006).

Given the bidirectional relationship between emotions and goal pursuit, it is not surprising that individual differences in emotional experiences have implications for selfregulation. For example, people who score high in neuroticism - those who experience more intense emotions, are more prone to negative emotional experiences — approach goals differently as a function of their amplified experience of risk and reward (Depue \& Collins, 1999). This can both undermine and facilitate self-regulation; more critical self-evaluation associated with neuroticism can actually help people achieve goals (Tamir, 2005). Another individual difference in emotionality that has implications for self-regulation is emotion regulation. Individuals differ in how, and how well, they control their emotions, including the strategies that they tend to use. People who struggle to regulate their emotions show impairments in self-regulation, as manifested in poorer well-being and interpersonal functioning (Gross \& John, 2003). This makes sense, as people often regulate their emotions for instrumental reasons; achieving specific emotional states can help people achieve other goals (e.g., Tamir, Chiu, \& Gross, 2007). People's choice of emotion regulation strategies can also have self-regulatory implications. For example, people who use substances to regulate their negative affect suffer more consequences associated with their use (e.g., Merill, Wardell, Read, 2014). A third individual difference in emotional states that is relevant to self-regulation is subjective well-being. A basic implication of theories that locate negative affect as a causal driver of behavioral change is that the absence of negative affect slows self-regulatory progress. When people are making good progress that they are satisfied with, they "coast," or devote less effort to the goal (Carver, 2003; Fitzsimons, Friesen, Orehek \& Kruglanksi, 2009). Similarly, it may be the case that people who are 
extremely content are less effective self-regulators than those with high but slightly lower subjective well-being. There is some evidence to suggest that this is indeed the case; for example, people whose baseline emotional state is extremely positive may take more health risks (e.g., Martin, Friedman, Tucker, Tomlinson-Keasy, Criqui, \& Schwartz, 2002) and work with less diligence towards their goals, resulting in slightly lower incomes and educational attainment (Oishi, Diener, \& Lucas, 2007).

\section{Risk and Reward Sensitivity}

Motivation is a construct that is operationalized differently across the psychological sciences and even within the self-regulation literature. Here, we consider individual differences that relate to people's motives, which encompass their goals and desires, as well as their style of goal pursuit. Although the target and style of goal pursuit varies by domain and is sensitive to situations, people show stable patterns in how they tend to relate to goals and the sorts of goals they are drawn to. Most basically, people differ in how they experience and relate to risk and reward (Gray, 1981). Independent trait sensitivity to risk and reward, or individual differences in the behavioral inhibition system and the behavioral activation system (BIS/BAS), respectively, emerge in early life and have broad consequences for self-regulation (Blair, 2003; Carver, 2006). These systems, which form the neurological basis of avoidance and approach behavior, are inherently self-regulatory; they modulate behavior with respect to the most basic goal: survival. Accordingly, extreme levels of responsiveness to both risk and reward create unique selfregulatory challenges. People who are very sensitive to risk are prone to experience more negative emotions (e.g., fear) and can be so motivated to avoid punishment and so vigilant to detect harm that they experience psychopathological levels of anxiety. People who are insufficiently sensitive to risk are less responsive to threats, including threats to their goals. 
Monitoring environments and behavior for potential self-control conflicts explains variance in everyday self-control failure (Myrseth \& Fishbach, 2009). People with underactive BIS may be vulnerable to self-control failures of this variety because they are relatively less inclined to monitor their environment for potential adverse events, including those related to goal pursuit and self-regulation (e.g., Amodio, Master, Yee, Taylor, 2008). Extreme sensitivity to reward is also a major threat to adaptive self-regulation and is strongly associated with impulsivity (Zuckerman, 1994). Reward sensitivity is implicated in disorders characterized by uncontrolled behavior such as overeating (e.g., Davis, Patte, Levitan, Reid, Tweed, \& Curtis, 2007), substance use (e.g., Franken \& Muris, 2006) and gambling (Reuter, Raedler, Rose, Hand, Gläscher, \& Büchel, 2005). In addition, specific combinations of BIS and BAS have implications for selfregulation. High BAS in combination with low BIS is a particularly problematic, and seems to exacerbate the vulnerabilities associated with extreme responsiveness to reward.

\section{Other Relevant Individual Differences}

Not all individual differences of relevance to self-regulation fit cleanly into one of the categories used in the previous section to organize the review of specific tendencies and traits. In this final section of the chapter, we review several additional constructs that either span categories or concern preferences for how goal pursuit is managed.

\section{Conscientiousness}

Unlike the constructs we have reviewed to this point, conscientiousness is not one construct. Rather, it is a collection of personality traits, or facets, with substantial relevance for self-regulation. The conscientiousness personality domain is parsed in different ways by different personality models and perspectives. The most influential perspective is reflected in conscientiousness as assessed by the NEO-PI-R, which comprises six facets (Costa \& McCrae, 
1992). Each facet has self-evident relevance for self-regulation. Individual differences in competence capture variability in people's confidence in their ability to get things done.

Orderliness reflects a preference for order that manifests as organization, tidiness, and neatness. Dutifulness, or responsibility, reflects a propensity to follow rules and fulfill obligations. People who are high on the achievement striving facet are prone toward working hard in order to achieve success. Perhaps most directly relevant for self-regulation is the self-discipline facet, which refers to the ability to persist at difficult or unpleasant tasks in order to complete them promptly. Deliberation is the tendency to think carefully before acting. An alternative approach to assessing conscientiousness, the BFI-2, posits three facets—organization, productiveness, and responsibility — which roughly correspond to the NEO-PI-R facets of orderliness, self-discipline, and dutifulness (Soto \& John, 2017). A factor analysis of multiple measures and ratings of conscientiousness yielded additional facets and more specific versions of the NEO-PI-R facets (MacCann, Duckworth, \& Roberts, 2009). Additional facets of particular relevance to selfregulation include perfectionism and task-planning.

The facets of conscientiousness identify characteristic patterns of behavior that support (McCrae \& Löckenhoff, 2010) and, at least partially, define (Eisenberg, Duckworth, Spinrad, \& Valiente, 2014) self-regulation. Empirically, individual differences in the conscientiousness facets are associated with effort expenditure, persistence, and efficiency of time use (ChamorroPremuzic \& Furnham, 2003; Kelly \& Johnson, 2005). In addition to these associations with basic processes involved in self-regulation, the facets are associated with specific outcomes and behaviors that reflect effective self-regulation. For example, the industriousness and control (i.e., low impulsivity) facets, despite very small correlations with cognitive ability, predict university grade point average (Rikoon et al., 2016). Individual differences in self-discipline are associated 
with wellness behaviors after accounting for a general latent conscientiousness factor (HaggerJohnson \& Whiteman, 2007). This finding illustrates an important consideration in research on the associations between conscientiousness and behaviors that reflect good self-regulation. Despite the appealing parsimony of referring to conscientiousness as a unitary trait, it is a personality domain whose content is best understood with reference to the specific traits that define the domain. When considered at that level, it is evident not only that conscientiousness is associated with self-regulation but also that it affects different aspects of the self-regulation process.

\section{Preferences for How Goal Pursuit is Managed}

The individual differences we have reviewed so far, though relevant for self-regulation, are not part and parcel of the self-regulatory process. They are predictive of typical success or failure at self-regulation but they offer little insight into variability in how people self-regulate. In this section, we review three individual differences that capture people's preferences for enacting one or more aspects of the self-regulatory process. Although these preferences may contribute to greater or lesser effectiveness of self-regulation under particular circumstances, they generally do not differentiate people in terms of routine effectiveness at self-regulation. Rather, they differentiate people on the basis of how they prefer to approach or manage goal pursuit.

\section{Regulatory Focus}

Regulatory focus theory proposes two general concerns underlying self-regulationpromotion and prevention - each of which may involve approach or avoidance (Strauman \& Wilson, 2010). Although every individual may, at times, be guided by either concern, and some situations and decision contexts pull for one or the other, individuals vary in their typical or 
preferred self-regulation concern. Those who favor promotion are more concerned with obtaining positive outcomes and focused on growth and achievement. Those who favor prevention are more oriented toward avoiding negative outcomes and focused on duties and responsibilities (Higgins, 1998). Importantly, attention to either concern can result in successful management of goal pursuit (Scholer \& Higgins, 2010). Promotion manifests as eagerness when goal pursuit meets with challenge; prevention manifests as vigilance in the face of challenge (Higgins, Friedman, Harlow, Idson, Ayduk, \& Taylor, 2001). Thus, people’s characteristic regulatory focus affects their preferred strategies for goal pursuit and their reaction to challenges in the course of pursuit.

\section{Regulatory Mode}

Regulatory mode concerns two fundamental and independent aspects of self-regulation: assessment and locomotion (Kruglanski et al., 2000). Assessment concerns processes associated with comparison in self-regulation-specifically, comparisons between alternative goals or means to achieving goals. Locomotion refers to processes in self-regulation that involve moving from the current state toward another state. In regulatory mode theory, these modes are independent; that is, concern for one has no implications for concern for the other. The preference for one mode or the other is evident at different stages of the self-regulatory process, with assessment most relevant for planning and evaluation, and locomotion most relevant for performance. Temperament and experience govern the degree to which individuals differ in their concern for each in the course of self-regulation (for a review, see Kruglanski, Orehek, Higgins, Pierro, \& Shalev, 2010).

\section{Action Control}


If an intention to act in a goal-consistent manner is to be translated into action, it must be protected from alternative action tendencies within the person and in the immediate environment. Action control processes such as selective attention, motivation control, and control of the environment provide the protection needed to ensure that goal-consistent intentions produce goal-consistent actions (Kuhl, 1985). Action control theory posits two motivational orientations that manifest as states and, relevant to our review, characterizes general tendencies that influence self-regulation. People who are action oriented have a high capacity to self-regulate their thoughts, feelings, and behaviors in such a way that their goal-relevant intentions lead to actions that promote progress in goal pursuit. People who are state oriented tend to focus either on their current states or on future states but do not routinely engage in the assessment of gaps between the two and strategies for narrowing those gaps. As a result, their goal-relevant intentions do not routinely translate into actions that move them toward their goals. In general, action-oriented people are more likely to shield themselves from intentions inconsistent with active goals, and therefore tend to be more focused and decisive with respect to their goals, than their stateoriented counterparts (Koole, 2004).

\section{Conclusion}

The voluminous literature on self-regulation has largely focused on the psychological mechanisms that are common to all people whose ability to self-regulate is not impaired by deficits or disorder. Although a focus on features of self-regulation that are fundamental and invariant across people is warranted, it seems evident that people vary considerably in their standing on an array of individual differences that are advantageous or problematic for effective self-regulation. Beyond their influence on effectiveness, individual differences affect how people routinely approach the self-regulation of their behavior. As such, two people who are equally 
effective at self-regulation may approach the setting and pursuit of goals in very different ways. In this chapter, we reviewed a subset of the potentially large number of individual differences that are relevant for self-regulation either because they contribute to its effectiveness or to preferences in how it is enacted.

The individual differences perspective on self-regulation complements and extends the traditional process perspective. It highlights the obvious but frequently ignored truth that the process of self-regulation comes easier to some people than to others. People who are high in self-control, dispositionally persistent, future focused, emotionally stable, self-disciplined, and action oriented enjoy the self-regulatory advantages of cognitive, emotional, and behavioral tendencies consistent with effective management of goal pursuit. Conversely, people who are impulsive, prone to ruminate or worry, disorganized, and anchored in the moment face an uphill battle in managing goal pursuit. Nonetheless, it is evident that not every person well-equipped for effective self-regulation routinely achieves it. Nor does every person who, dispositionally, seems poorly equipped for effective self-regulation routinely fail to achieve it. For these reasons, the process and individual-difference perspectives must be integrated with a yet-to-be-articulated perspective on the role of environment, including other people, to provide a full account of effective self-regulation. 


\section{References}

Amodio, D. M., Master, S. L., Yee, C. M., \& Taylor, S. E. (2008). Neurocognitive components of the behavioral inhibition and activation systems: Implications for theories of selfregulation. Psychophysiology, 45, 11-19.

Bandura, A. (1991). Social cognitive theory of self-regulation. Organizational Behavior and Human Decision Processes, 50, 248-287.

Baumeister, R. F., Bratslavsky, E., Muraven, M., \& Tice, D. M. (1998). Ego depletion: Is the active self a limited resource? Journal of Personality and Social Psychology, 74, 12521265.

Baumeister, R. F., Zell, A. L., \& Tice, D. M. (2007). How emotions facilitate and impair selfregulation. In J. J. Gross (Ed.), Handbook of emotion regulation (pp. 408-426). New York: Guilford Press.

Berkman, E. T., Livingston, J. L. \& Kahn, L. E. (2017). Finding the "self” in self-regulation: The identity-value model. Psychological Inquiry, 28, 77-98.

Berns, G. S., Laibson, D., \& Loewenstein, G. (2007). Intertemporal choice: Toward an integrative framework. Trends in Cognitive Sciences, 11, 482-488.

Blair, C. (2003). Behavioral inhibition and behavioral activation in young children: Relations with self-regulation and adaptation to preschool in children attending Head Start. Developmental Psychobiology, 42, 301-311.

Blair, C., \& Raver, C. C. (2015). School readiness and self-regulation: A developmental psychobiological approach. Annual Review of Psychology, 66, 711-731. 
Brandstätter, V., \& Schüler, J. (2013). Action crisis and cost-benefit thinking: A cognitive analysis of a goal-disengagement phase. Journal of Experimental Social Psychology, 49, $543-553$.

Brown, J. D. (1998). The self. New York: McGraw-Hill.

Brown, J. M., Miller, W. R., \& Lawendowski, L. A. (1999). The Self-Regulation Questionnaire. In L. VandeCreek \& T. L. Jackson (Eds.), Innovations in clinical practice: A source book (Vol. 17, pp. 281-289). Sarasota, FL: Professional Resource Press.

Carver, C. S. (2003). Pleasure as a sign you can attend to something else: Placing positive feelings within a general model of affect. Cognition and Emotion, 17, 241-261.

Carver, C. S. (2006). Approach, avoidance, and the self-regulation of affect and action. Motivation and Emotion, 30, 105-110.

Carver, C. S., \& Scheier, M. F. (1982). Control theory: A useful conceptual framework for personality-social, clinical, and health psychology. Psychological Bulletin, 92, 111-135.

Carver, C. S., \& Scheier, M. F. (2014). Dispositional optimism. Trends in Cognitive Sciences, 18, 293-299.

Carver, C. S., Scheier, M. F., \& Weintraub, J. K. (1989). Assessing coping strategies: A theoretically based approach. Journal of Personality and Social Psychology, 56, 267-283.

Chamorro-Premuzic, T., \& Furnham, A. (2003). Personality predicts academic achievement: Evidence from two longitudinal university samples. Journal of Research in Personality, 37, 319-338.

Cloninger, C. R., Przybeck, T. R., Svrakic, D. M., \& Wetzel, R. D. (1994). The Temperament and Character Inventory (TCI): A guide to its development and use. St Louis, MO: Center for Psychobiology of Personality. 
Costa, P. T., Jr., \& McCrae, R. R. (1992). Normal personality assessment in clinical practice: The NEO Personality Inventory. Psychological Assessment, 4, 5-13.

Davey, G. C. L. (1994). Pathological worrying as exacerbated problem-solving. In G. C. L. Davey \& F. Tallis (Eds.), Worrying: Perspectives on theory, assessment, and treatment (pp. 35-59). New York: Wiley.

Davis, C., Patte, K., Levitan, R., Reid, C., Tweed, S., \& Curtis, C. (2007). From motivation to behaviour: A model of reward sensitivity, overeating, and food preferences in the risk profile for obesity. Appetite, 48, 12-19.

Depue, R. A., \& Collins, P. F. (1999). Neurobiology of the structure of personality: Dopamine, facilitation of incentive motivation, and extraversion. Behavioral and Brain Sciences, 22, 491-517.

Dickman, S. J. (1990). Functional and dysfunctional impulsivity: Personality and cognitive correlates. Journal of Personality and Social Psychology, 58, 95-102.

Dolcos, F., \& McCarthy, G. (2006). Brain systems mediating cognitive interference by emotional distraction. Journal of Neuroscience, 26, 2072-2079.

Duckworth, A. L. (2011). The significance of self-control. Proceedings of the National Academy of Sciences, 108, 2639-2640.

Duckworth, A. L., Peterson, C., Matthews, M. D., \& Kelly, D. R. (2007). Grit: Perseverance and passion for long-term goals. Journal of Personality and Social Psychology, 92, 10871101.

Eisenberg, N., Duckworth, A. L., Spinrad, T. L., \& Valiente, C. (2014). Conscientiousness: Origins in childhood? Developmental Psychology, 50, 1331-1349. 
Fishbach, A. \& Zhang, Y., (2009). The dynamics of self-regulation: When goals commit versus liberate. In M. Wänke (Ed.), The social psychology of consumer behavior (pp. 365-386), NY: Psychology Press.

Fitzsimons, G. M., Friesen, J., Orehek, E., \& Kruglanski, A. W. (2009). Progress-induced goal shifting as a self-regulatory strategy. In J. P. Forgas, R. F. Baumeister, \& D. M. Tice (Eds.), The Sydney symposium of social psychology: Vol. 11. Psychology of selfregulation: Cognitive, affective, and motivational processes (pp. 183-197). New York: Psychology Press.

Franken, I. H., \& Muris, P. (2006). BIS/BAS personality characteristics and college students' substance use. Personality and Individual Differences, 40, 1497-1503.

Gollwitzer, P. M., Parks-Stamm, E. J., Jaudas, A., \& Sheeran, P. (2007). Flexible tenacity in goal pursuit. In J. Y. Shah (Ed.), Handbook of motivation science (pp. 325-341). New York: Guilford.

Gray, J. A. (1981). A critique of Eysenck's theory of personality. In H. J. Eysenck (Ed.), A model for personality (pp. 246-276). Berlin: Springer-Verlag.

Gross, J. J., \& John, O. P. (2003). Individual differences in two emotion regulation processes: Implications for affect, relationships, and well-being. Journal of Personality and Social Psychology, 85, 348-362.

Hagger-Johnson, G. E., \& Whiteman, M. C. (2007). Conscientiousness facets and health behaviors: A latent variable modeling approach. Personality and Individual Differences, $43,1235-1245$.

Higgins, E. T. (1998). Promotion and prevention: Regulatory focus as a motivational principle. Advances in Experimental Social Psychology, 30, 1-46. 
Higgins, E. T., Friedman, R. S., Harlow, R. E., Idson, L. C., Ayduk, O. N., \& Taylor, A. (2001). Achievement orientations from subjective histories of success: Promotion pride versus prevention pride. European Journal of Social Psychology, 31, 3-23.

Hofmann, W., Baumeister, R. F., Förster, G., \& Vohs, K. D. (2012). Everyday temptations: An experience sampling study of desire, conflict, and self-control. Journal of Personality and Social Psychology, 102, 1318-1335.

Hofmann, W., Gschwendner, T., Friese, M., Wiers, R. W., \& Schmitt, M. (2008). Working memory capacity and self-regulatory behavior: Toward an individual differences perspective on behavior determination by automatic versus controlled processes. Journal of Personality and Social Psychology, 95, 962-977.

Hofmann, W., Schmeichel, B. J., \& Baddeley, A. D. (2012). Executive functions and selfregulation. Trends in Cognitive Sciences, 16, 174-180.

Hoyle, R. H., \& Davisson, E. K. (2016). Varieties of self-control and their personality correlates. In K. D. Vohs \& R. F. Baumeister (Eds.), Handbook of self-regulation: Research, theory, and applications (3rd ed., pp. 396-413). New York: Guilford Press.

Hoyle, R. H., Fejfar, M. C., \& Miller, J. D. (2000). Personality and sexual risk taking: A quantitative review. Journal of Personality, 68, 1203-1231.

Ilkowska, M., \& Engle, R. W. (2010). Trait and state differences in working memory capacity. In A. Gruszka, G. Matthews, \& B. Szymura (Eds.), Handbook of individual differences in cognition: Attention, memory, and executive control (pp. 295-320). New York: Springer.

Inzlicht, M., Bartholow, B. D., \& Hirsh, J. B. (2015). Emotional foundations of cognitive control. Trends in Cognitive Sciences, 19, 126-132. 
Inzlicht, M., \& Schmeichel, B. J. (2016). Beyond limited resources: Self-control failure as the product of shifting priorities. In K. D. Vohs \& R. F. Baumeister (Eds.), Handbook of selfregulation: Research, theory, and applications (3rd ed., pp. 165-181). New York: Guilford Press.

Kahneman, D., \& Klein, G. (2009). Conditions for intuitive expertise: A failure to disagree. American Psychologist, 64, 515-526.

Kanfer, F. H. (1970a). Self-monitoring: Methodological limitations and clinical applications. Journal of Consulting and Clinical Psychology, 35, 148-152.

Kanfer, F. H. (1970b). Self-regulation: Research, issues, and speculation. In C. Neuringer \& J. L. Michael (Eds.), Behavior modification in clinical psychology (pp. 178-220). New York: Appleton-Century-Crofts.

Karoly, P. (1993). Mechanisms of self-regulation: A systems view. Annual Review of Psychology, 44, 23-52.

Kelly, W. E., \& Johnson, J. L. (2005). Time use efficiency and the five-factor model of personality. Education, 125, 51-515.

Klinger, E. (1975). Consequences of commitment to and disengagement from incentives. Psychological Review, 82, 1-25.

Koole, S. L. (2004). Volitional shielding of the self: Effects of action orientation and external demands on implicit self-evaluation. Social Cognition, 22, 100-125.

Kruglanski, A. W., Orehek, E., Higgins, E. T., Pierro, A., \& Shalev, I. (2010). Modes of selfregulation: Assessment and locomotion as independent determinants in goal pursuit. In R. H. Hoyle (Ed.), Handbook of personality and self-regulation (pp. 375-402). Malden, MA: Wiley-Blackwell. 
Kruglanski, A. W., Thompson, E. P., Higgins, E. T., Atash, M. N., Pierro, A., Shah, J. Y., \& Spiegel, S. (2000). To "do the right thing" or to "just do it": Locomotion and assessment as distinct self-regulatory imperatives. Journal of Personality and Social Psychology, 79, 793-815.

Kuhl, J. (1985). Volitional mediators of cognition-behaviour consistency: Self-regulatory processes and action versus state orientation. In J. Kuhl \& J. Beckmann (Eds.), Action control: From cognition to behaviour (pp. 101-128). New York: Springer.

Locke, E. A., \& Latham, G. P. (2006). New directions in goal-setting theory. Current Directions in Psychological Science, 15, 265-268.

MacCann, C., Duckworth, A. L., \& Roberts, R. D. (2009). Empirical identification of the major facets of conscientiousness. Learning and Individual Differences, 19, 451-458.

Martin, L. R., Friedman, H. S., Tucker, J. S., Tomlinson-Keasey, C., Criqui, M. H., \& Schwartz, J. E. (2002). A life course perspective on childhood cheerfulness and its relation to mortality risk. Personality and Social Psychology Bulletin, 28, 1155-1165.

McCrae, R. R., \& Löckenhoff, C. E. (2010). Self-regulation and the five-factor model of personality traits. In R. H. Hoyle (Ed.), Handbook of personality and self-regulation (pp. 145-168). Malden, MA: Wiley-Blackwell.

Metcalfe, J., \& Mischel, W. (1999). A hot/cool-system analysis of delay of gratification: Dynamics of willpower. Psychological Review, 106, 3-19.

Merrill, J. E., Wardell, J. D., \& Read, J. P. (2014). Drinking motives in the prospective prediction of unique alcohol-related consequences in college students. Journal of Studies on Alcohol and Drugs, 75, 93-102. 
Miller, W. R., \& Brown, J. M. (1991). Self-regulation as a conceptual basis for the prevention and treatment of addictive behaviours. In N. Heather, W. R. Miller \& J. Greeley (Eds.), Self-control and the addictive behaviours (pp. 3-79). Sydney: Maxwell Macmillan Publishing Australia.

Mischel, W., Shoda, Y., \& Peake, P.K. (1988). The nature of adolescent competencies predicted by preschool delay of gratification. Journal of Personality and Social Psychology, 54, 687-696.

Miyake, A., Friedman, N. P., Emerson, M. J., Witzki, A. H., Howerter, A., \& Wager, T. D. (2000). The unity and diversity of executive functions and their contributions to complex "frontal lobe" tasks: A latent variable analysis. Cognitive psychology, 41, 49-100.

Muraven, M., \& Baumeister, R. F. (2000). Self-regulation and depletion of limited resources: Does self-control resemble a muscle? Psychological Bulletin, 126, 247-259.

Myrseth, K. O. R., \& Fishbach, A. (2009). Self-control: A function of knowing when and how to exercise restraint. Current Directions in Psychological Science, 18, 247-252.

Nolen-Hoeksema, S. (1991). Responses to depression and their effects on the duration of depressive episodes. Journal of Abnormal Psychology, 100, 569-582.

Nolen-Hoeksema, S., Wisco, B. E., \& Lyubomirsky, S. (2008). Rethinking rumination. Perspectives on Psychological Science, 3, 400-424.

Oishi, S., Diener, E., \& Lucas, R. E. (2007). The optimum level of well-being: Can people be too happy?. Perspectives on Psychological Science, 2, 346-360.

Park, G., Schwartz, H. A., Sap, M., Kern, M. L., Weingarten, E., Eichstaedt, J. C., Berger, J., Stillwell, D. J., Kosinski, M., Ungar, L. H., \& Seligman, M. E. P. (2016). Living in the 
past, present, and future: Measuring temporal orientation with language. Journal of Personality, 85, 270-280.

Pessoa, L. (2009). How do emotion and motivation direct executive control? Trends in Cognitive Sciences, 13, 160-166.

Porath, C. L., \& Bateman, T. S. (2006). Self-regulation: From goal orientation to job performance. Journal of Applied Psychology, 91, 185.

Reuter, J., Raedler, T., Rose, M., Hand, I., Gläscher, J., \& Büchel, C. (2005). Pathological gambling is linked to reduced activation of the mesolimbic reward system. Nature Neuroscience, 8, 147-148.

Rikoon, S. H., Brennemana, M., Kim, L. E., LaleKhorramdel, L., MacCann, C., Burrus, J., \& Roberts, R. D. (2016). Facets of conscientiousness and their differential relationships with cognitive ability factors. Journal of Research in Personality, 61, 22-34

Rothstein, M. G., McLarnon, M. J. W., \& King, G. (2016). The role of self-regulation in workplace resiliency. Industrial and Organizational Psychology: Perspectives on Science and Practice, 9, 416-421.

Rotter, J. B. (1954). Social learning and clinical psychology. Englewood Cliffs, NJ: PrenticeHall.

Scholer, A. A., \& Higgins, E. T. (2010). Regulatory focus in a demanding world. In R. H. Hoyle (Ed.), The handbook of personality and self-regulation (pp. 291-314). Malden, MA: Wiley-Blackwell.

Schwarzer, R. (1994). Optimism, vulnerability, and self-beliefs as health-related cognitions: A systematic overview. Psychology and Health: An International Journal, 9, 161-180. 
Schwarzer R., \& Jerusalem M. (1995). Optimistic self-beliefs as a resource factor in coping with stress. In S. E. Hobfoll \& M. W. de Vries (Eds.), Extreme stress and communities: Impact and intervention (pp. 159-177). Dordrecht: Springer.

Seeyave, D. M., Coleman, S., Appugliese, D., Corwyn, R. F., Bradley, R. H., Davidson, N .S., Kaciroti, N., \& Lumeng, J. C. (2009). Ability to delay gratification at age 4 years and risk of overweight at age 11 years. Archives of Pediatrics and Adolescent Medicine, 163, 303308.

Segerstrom, S. C., Roach, A. R., Evans, D. R., Schipper, L. J., \& Darville, A. K. (2010). The structure and health correlates of trait repetitive thought in older adults. Psychology and Aging, 25, 505-515.

Segerstrom, S. C., Tsao, J. C. I., Alden, L. E., \& Craske, M. G. (2000). Worry and rumination: Repetitive thought as a concomitant and predictor of negative mood. Cognitive Therapy and Research, 24, 671-688.

Servaas, M. N., Riese, H., Ormel, J., \& Aleman, A. (2014). The neural correlates of worry in association with individual differences in neuroticism. Human Brain Mapping, 35, 43034315.

Sevincer, A. T., Mehl, P. J., \& Oettingen, G. (2017). Well self-regulated people use mental contrasting. Social Psychology, 48, 348-364.

Shipstead, Z., Redick, T. S., \& Engle, R. W. (2012). Is working memory training effective?. Psychological Bulletin, 138, 628.

Shoda, Y., Mischel, W., \& Peake, P. K. (1990). Predicting adolescent cognitive and selfregulatory competencies from preschool delay of gratification: Identifying diagnostic conditions. Developmental Psychology, 26, 978-986. 
Simons, D. J., Boot, W. R., Charness, N., Gathercole, S. E., Chabris, C. F., Hambrick, D. Z., \& Stine-Morrow, E. A. (2016). Do "brain-training” programs work? Psychological Science in the Public Interest, 17, 103-186.

Soto, C. J., \& John, O. P. (2017). The next Big Five Inventory (BFI-2): Developing and assessing a hierarchical model with 15 facets to enhance bandwidth, fidelity, and predictive power. Journal of Personality and Social Psychology, 113, 117-143.

Strathman, A., Gleicher, F., Boninger, D. S., \& Edwards, C. S. (1994). The consideration of future consequences: Weighing immediate and distant outcomes of behavior. Journal of Personality and Social Psychology, 66, 742-752.

Strauman, T. J., \& Wilson, W. A. (2010). Behavioral activation/inhibition and regulatory focus as distinct levels of analysis. In R. H. Hoyle (Ed.), Handbook of personality and selfregulation (pp. 447-473). Malden, MA: Blackwell.

Tamir, M. (2005). Don't worry, be happy? Neuroticism, trait-consistent affect regulation, and performance. Journal of Personality and Social Psychology, 89, 449-461.

Tamir, M., Chiu, C. Y., \& Gross, J. J. (2007). Business or pleasure? Utilitarian versus hedonic considerations in emotion regulation. Emotion, 7, 546-554.

Tice, D. M., \& Bratslavsky, E. (2000). Giving in to feel good: The place of emotion regulation in the context of general self-control. Psychological Inquiry, 11, 149-159.

vanDellen, M. R., Shah, J. Y., Leander, N. P., Delose, J. E., \& Bornstein, J. X. (2015). In good company: Managing interpersonal resources that support self-regulation. Personality and Social Psychology Bulletin, 41, 869-882. 
Wang, K., Wei, D., Yang, J., Xie, P., Hao, X., \& Qiu, J. (2015). Individual differences in rumination in healthy and depressive samples: Association with brain structure, functional connectivity and depression. Psychological Medicine, 45, 2999-3008.

Whiteside, S. P., \& Lynam, D. R. (2001). The five factor model and impulsivity: Using a structural model of personality to understand impulsivity. Personality and Individual Differences, 30, 669-689.

Weiner, B. (1979). A theory of motivation for some classroom experiences. Journal of Educational Psychology, 71, 3-25.

Weiner, B. (1992). Human motivation: Metaphors, theories, and research. Newbury Park, CA: Sage Publications.

Wittmann, M., \& Paulus, M. P. (2008). Decision making, impulsivity and time perception. Trends in Cognitive Sciences, 12, 7-12.

Wilson, T. D., \& Gilbert, D. T. (2003). Affective forecasting. Advances in Experimental Social Psychology, 35, 345-411.

Wrosch, C., Scheier, M. F., Miller, G. E., Schulz, R., \& Carver, C. S. (2003). Adaptive selfregulation of unattainable goals: Goal disengagement, goal reengagement, and subjective well-being. Personality and Social Psychology Bulletin, 29, 1494-1508.

Zuckerman, M. (1994). Behavioral expressions and biosocial bases of sensation seeking. New York: Cambridge University Press. 